\title{
Beyond geometries of activity spaces: A holistic study of daily travel patterns, individual characteristics, and perceived wellbeing in Helsinki metropolitan area
}

\author{
Kamyar Hasanzadeh \\ Aalto University \\ Kamyar.hasanzadeh@aalto.fi \\ Jukka Heinonen \\ University of Iceland \\ heinonen@hi.is \\ Sanna Ala-Mantila \\ University of Helsinki \\ sanna.ala-mantila@helsinki.fi
}

\author{
Michal Czepkiewicz \\ University of Iceland \\ michal.czepkiewicz@gmail.com \\ Marketta Kyttä \\ Aalto University \\ marketta.kytta@aalto.fi \\ Juudit Ottelin \\ Aalto University \\ juudit.ottelin@aalto.fi
}

\begin{abstract}
Activity space (AS) is a measure of spatial behavior used to summarize the mobility behavior of individuals. Current studies often highlight the fact that AS is highly complex and multidimensional in character. Therefore, the need for more holistic approaches providing more comprehensive descriptions of mobility patterns is evident. This article assesses the activity spaces of young adults aged 25-40 living in the Helsinki metropolitan area using a dataset collected with an online map survey. Using a wide range of measurements covering different aspects of AS, we identified seven components that define activity spaces, namely size, intensity of activities, volume of trips, exteriority, polycentricity, elongation, and destination specialization. We then used the components together with travel mode use to identify a typology of daily mobility patterns. The results show that individuals with different types of AS differ significantly in their socio-demographic characteristics, such as age, gender, employment, household characteristics, and residential neighborhood. Furthermore, the study reveals interesting associations between AS characteristics and different aspects of wellbeing. Overall, the results highlight the importance of multidimensional and comprehensive approaches to understanding daily mobility of urban residents.
\end{abstract}

\section{Introduction}

Understanding mobility patterns has long been an important topic in various fields of study (Kwan \& Schwanen, 2016). In recent decades, the interest has been on issues related to sustainability and sustainable urban mobility in particular (Banister, 2008). Specific focus has been put on motorized urban

Copyright 2019 Kamyar Hasanzadeh, Michal Czepkiewicz, Jukka Heinonen, Marketta Kyttä, Sanna Ala-Mantila, \& Juudit Ottelin http://dx.doi.org/10.5198/jtlu.2019.1148

ISSN: 1938-7849 | Licensed under the Creative Commons Attribution - Noncommercial License 4.0

The Journal of Transport and Land Use is the official journal of the World Society for Transport and Land Use (WSTLUR) and is published and sponsored by the University of Minnesota Center for Transportation Studies. 
travel as an important source of greenhouse gas emissions (Millard-Ball \& Schipper, 2011) and one of the factors affecting public health and individual well-being (Handy, Boarnet, Ewing, \& Killingsworth, 2002; Northridge \& Freeman, 2011). In this policy context, an important line of research focuses on explaining mobility patterns with urban form and their socioeconomic and psychological characteristics (e.g., Buliung \& Kanaroglou, 2006; Ewing \& Cervero, 2010; Naess, 2012). The measures most commonly used to describe the degree and nature of mobility include total distances travelled and mode choice (Ewing \& Cervero, 2010; Naess, 2012). Mode choice is also a common measure of travel behavior in well-being and health-related research (Pucher, Buehler, Bassett, \& Dannenberg, 2010). However, variables describing travel behavior in these studies often capture only one of its aspects. Therefore, they do not represent its overall complexity (Hanson \& Hanson, 1981; Kwan, 2012a; Perchoux et al., 2014). This study takes a more holistic approach to measuring travel behavior using the notion of activity spaces.

Activity space (AS) is a concept used to describe the spatial behavior of individuals. It is widely used to describe a person's mobility (Perchoux et al., 2014; Sherman, Spencer, Preisser, Gesler, \& Arcury, 2005) or to identify locations where people are in direct contact with as a result of their mobility (Kwan, 2012a; Horton \& Reynolds, 1971). ASs have been applied in a diversity of fields, including transportation research, geography, public health, and social segregation studies (Patterson \& Farber, 2015). Particularly, there is a growing body of evidence on links between AS characteristics and different aspects of wellbeing. More specifically, researchers have been studying ASs in relation to their underlying socio-economical and structural characteristics to examine people's mobility behavior and explore its associations with health (Bertram \& Rehdanz, 2015; Lee et al., 2015; Richardson, Pearce, Mitchell, \& Kingham, 2013; Vallée, Cadot, Roustit, Parizot, \& Chauvin, 2011). Despite the relatively broad application of AS in research, the majority of studies thus far have used single -or limited-measures of it to describe these associations.

At the same time, travel behavior is complex and multidimensional in character (Hanson \& Hanson, 1981; Kwan, 2012a). As Sherman et al. note (2005), different methods for measuring activity spaces can yield different results and lead to different conclusions, none of which is necessarily better or worse than the next. With the increasing diversity of AS measures used in literature, there is a growing need for more holistic approaches incorporating different analytical methods. However, few studies thus far have taken such an approach by using multiple measures, acknowledging their limitations, and simultaneously looking at various dimensions of mobility behavior (Perchoux et al., 2014).

This study is primarily motivated by this research gap and it aims to take a multidimensional and holistic approach to address the issue. As its primary objective, this study explores various AS dimensions and implements an analytical framework to improve our understanding of individual mobility and spatial behavior. At the same time, the framework is applied empirically to explore the relationships between daily mobility patterns, characteristics of individuals, and their perceived wellbeing. This is done using data on the daily travel patterns of young adults in the Helsinki metropolitan area (HMA), collected through an online map-based survey.

As illustrated in Figure 1, using the empirical case study, we pursue three research aims. First, we describe the ASs of HMA residents using a multidimensional approach. Second, we create a novel typology of daily mobility patterns of HMA residents based on AS measures and travel mode use. And finally, we explore the relationships between AS descriptions and characteristics of individuals, such as socioeconomic variables, urban form in residential locations, and personal wellbeing. There is an extensive body of literature on the interrelationships between mobility patterns, socio-economic variables, urban form, and personal wellbeing. With the growing scholarly interest in the topic and the growing concerns related to the built environment, sedentary behavior, and their effects on personal wellbeing, there is little doubt about the relevance of such studies. However, these themes have rarely been scrutinized 
under a unified theoretical framework and in a multidimensional manner.

A major contribution of this study is to employ the proposed multidimensional approach to explore the associations between different AS characteristics and individuals' satisfaction with various life domains. This is done using a notion of subjective wellbeing that is based on the classical definition of it as an overall assessment of a person's quality of life (Shin \& Johnson, 1978). The World Health Organization defines quality of life as individual's perception of their position in life in relation to their goals, expectations, standards and concerns (WHOQOL, 1993). This is a broad concept affected by the person's physical health, psychological state, personal beliefs, social relationships and their relationship with their environment (Dodge, Daly, Huyton, \& Sanders, 2012; WHOQOL, 1993).

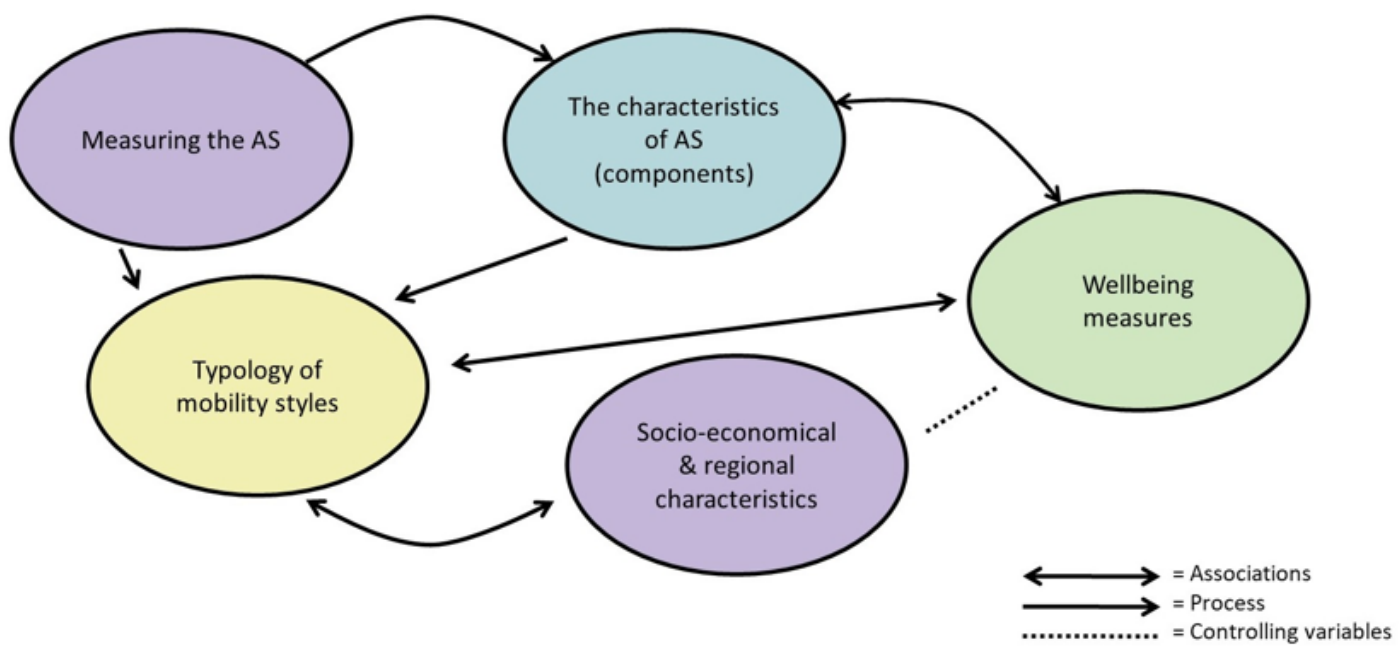

Figure 1. The conceptual framework of study

This study builds upon previous research and is informed by various methodological and empirical sources. Thus, the following section provides a brief review of AS measurements and the relationships between urban form, socio-demographics, and wellbeing.

\section{Background}

\subsection{Activity space measurement}

AS measurement and its application in social research is rooted in time geography (Hägerstraand, 1970; Perchoux, Chaix, Cummins, \& Kestens, 2013). Geometric size is perhaps the most common dimension of AS measurement (Jarv et al., 2015; Tana, Kwan, Chai, 2016). It is commonly measured as the area of a minimum convex polygon (MCP) covering all locations visited by an individual or household (e.g., Buliung \& Kanaroglou, 2006; Fan \& Khattak, 2008; Manaugh \& El-Geneidy, 2012), or a standard deviational ellipse (SDE) calculated using location coordinates (e.g., Jarv, Muurisepp, Ahas, Derudder, \& Witlox, 2015; Miranda-Moreno, Eluru, Lee-Gosselin, \& Kreider, 2012).

Another dimension that describes human behavior in space is its concentration around one or multiple centers. Contrary to size, it does not necessarily capture the degree or amount of mobility, but rather its concentration around specific locations. According to Flamm and Kaufmann (2006), personal networks of typical places consist of daily life centers and clusters of activity places. Daily life centers are 
places in which people spend considerable time and consider them important in their everyday lives, such as home or workplace. Minor activities, such as services and social activities, often cluster around these centers. The centers have also been described as activity anchor points (Dijst, 1999; Schönfelder \& Axhausen, 2003; Xu et al., 2016). The centers may be identified by the amount of time spent in them (Flamm \& Kaufmann, 2006), the frequency of visits, or based on whether they form spatial clusters with minor activity locations.

Elongation and Exteriority are two other measures that can capture information about the distribution of activities through space. Elongation is a geometrical characteristic that has previously been used in a number of AS studies and can be derived from a standard deviational ellipse (e.g., Buliung \& Kanaroglou, 2006; Perchoux et al., 2014). The exteriority measure may describe the concentration of activities in a residential neighborhood (Hasanzadeh, Laatikainen, \& Kyttä., 2018) or away from it.

Further measures address the non-geometrical aspects of ASs, such as the types of visited destinations, their diversity, and intensity. Intensity captures the total frequency of activities over a specific time frame (Perchoux et al., 2014). It does not capture how far people travel, but how often and how many locations they visit. Such measures have been used in studies that use mobile phone (e.g., Jarv et al., 2015; Xu et al., 2016) and GPS tracking data, as well as in online mapping surveys (Hasanzadeh, Broberg, \& Kyttä, 2017). Further, the number of activity types have been used to capture AS specialization around such purposes as shopping, work, or social activities (Perchoux et al., 2014). Travel mode share, which is a very common variable describing travel behavior (Ewing \& Cervero, 2010), has also been treated as an AS measure (Burnett \& Hanson, 1982; Hanson \& Hanson, 1981). More recently, it has also been used as an external variable related to certain AS characteristics (Perchoux et al., 2014).

Although most of the studies have used single measures of AS to describe mobility behavior, a few studies have used multiple measures, compared them, and discussed the differences in their interpretation (Patterson \& Farber, 2015). Several studies have discussed relationships between variables. For instance, Buliung and Kanaroglou (Buliung \& Kanaroglou, 2006) note that the size of AS is only distantly related to travelled distances, as people may frequently visit multiple locations that are close together. In an isolated effort, Perchoux et al. (2014) looked at the interrelationships between various measures and identified five components of AS measurement. The components included (in order of importance) "centering of the AS on the residential neighborhood," "size of the AS," "volume of activities," "specialization of the AS," and "elongation of the AS". Later, Hasanzadeh et al. (2018) and Laatikainen, Hasanzadeh, and Kyttä (2018) extend these dimensions by also considering urban structure and place exposure. However, to this end, component analyses of ASs do not include measures of their mono- or polycentric nature.

AS measures can also be synthesized as a way of creating typologies and segmentations, which may then be used for social marketing and transportation modeling (Flamm \& Kaufmann, 2006; Hanson \& Hanson, 1981; Prillwitz \& Barr, 2011). Although people's individuality and uniqueness should not be ignored, researchers have found that people often display a substantial number of similarities in many aspects of their lives (Haustein \& Hunecke, 2013). Therefore, researchers have long used segmentation as a tool for identifying these similarities in subgroups and classifying people accordingly. Comprehensive measurement of travel behavior, together with urban form and socio-demographic descriptors, may also help researchers identify distinct mobility styles (Prillwitz \& Barr, 2011). However, this has rarely been addressed in recent studies.

\subsection{Activity spaces, wellbeing, and urban form: Empirical findings}

Travel behavior patterns have been connected with various aspects of health and wellbeing. Social inclusion is one wellbeing domain that has often been linked to AS characteristics. In this line of research, inadequate access to or the high cost of transportation are thought to reduce access to opportunities, 
social networks, goods, and services (Kamruzzaman \& Hine, 2012; Kenyon, Lyons, \& Rafferty, 2002). Urban mobility is perceived as a means of social integration (Ohnmacht, Götz, \& Schad, 2009). It has been theorized that the size of an AS captures the degree of one's mobility and the spatial extent of one's network geography, and thus may be a proxy measure of social exclusion (Axhausen, 2003; Schönfelder \& Axhausen, 2003). However, there is little empirical evidence supporting this hypothesis. For instance, Schönfelder and Axhausen (2003) found no significant relationships between three different measures of AS size and the participation of groups at risk of social exclusion, such as people with low-income and older adults.

According to Perchoux et al. (2013), the relationship between AS size and social network geography has not been adequately demonstrated. This can be in fact the result of contradictory findings yielding from different studies. Several studies have reported negative associations between the extents of travel and participation in social activities (Farber \& Páez, 2009). This can be mainly due to the fact that larger ASs are likely to be driven by car use, while car use is found to impede individuals' social activity and increase privatization. At the same time, extensive daily travel may also improve social integration of some individuals depending on their lifestyle and personal attitudes (Ohnmacht et al., 2009).

Social wellbeing is not the only aspect of wellbeing that has been studied in relation to travel behavior. There is a growing number of studies concentrating on the use of active travel modes and its positive contribution to health. Accordingly, in recent years urban planning policies and studies on travel behavior have increasingly focused on limiting motorized travel and the associated environmental or social burdens (Banister, 2008; Frumkin, 2002). Walking and cycling are important sources of daily physical activity for many people, and thus may help reduce obesity and the risk of cardiovascular disease as well as improve general health (de Hartog, Boogaard, Nijland, \& Hoek, 2010; Pucher et al., 2010; Shephard, 2008). Cycling and walking have been found to enhance mood, whereas using public transportation or a car is more commonly associated with negative emotions (Gatersleben \& Uzzell, 2007; Morris \& Guerra, 2014).

In this context, several physical and structural characteristics of ASs are found to be associated with higher use of active travel modes, and in turn, better health outcomes. For instance, walkable neighborhoods with high density rates, greater diversity of land uses, and good access to services have been associated with higher modal shares of active travel and lower shares of car use (Creatore et al., 2016; Ewing \& Cervero, 2010; Glazier et al., 2014; Hoehner, Handy, Yan, Blair, \& Berrigan, 2011). Furthermore, Naess $(2012$; 2013) concludes that, besides neighborhood characteristics, a shorter distance from home to the city center and to local centers lowers car use. Similarly, several studies have shown that residents of more urban neighborhoods (i.e., centrally located, densely built, with good access to services) have smaller and less dispersed activity spaces than residents of suburbs or rural areas (Buliung \& Kanaroglou, 2006; Fan \& Khattak, 2008; Flamm \& Kaufmann, 2006; Harding, Patterson, Miranda-Moreno, \& Zahabi, 2012; Manaugh \& El-Geneidy, 2012; Schönfelder \& Axhausen, 2003). These characteristics are thought to be associated with the higher use of active travel modes and better health (Manaugh $\&$ El-Geneidy, 2012).

Furthermore, spatial dispersion, as an indicator of spatial concentration of activities, may either signify being "trapped in a neighborhood" or being able to find enough resources and opportunities without traveling far. In the same line, exteriority and elongation may be theoretically linked to commuting away from a local neighborhood, while being unable to access resources locally. In other words, long commutes from an individual's place of residence can result in a more elongated AS shape with a lower concentration of activities in immediate home surrounding. For instance, Buliung and Kanaroglou (2006) have found that inhabitants of suburban areas have more elongated ASs than residents of an urban core. According to some authors, long commutes from suburban neighborhoods may limit 
the time spent at home and in the residential area, thus negatively influencing relationships with one's family and local community (Putnam, 2000). Commuting not only negatively affects people's current mood (Kahneman, Krueger, Schkade, Schwarz, \& Stone, 2004), but also has a negative influence on individual and household satisfaction with life, which is not compensated for by higher incomes (Stutzer \& Frey, 2008).

Mobility patterns, including AS characteristics, are also determined by socioeconomic characteristics, life-cycle stage, household situation, as well as lifestyle orientations and personalities (Kamruzzaman \& Hine, 2012; Rainham, McDowell, Krewski, \& Sawada, 2010; Ohnmacht et al., 2009; van Acker, van Wee, \& Witlox, 2010). For instance, people who put value on their professional career and family may travel more to work- and childcare-related destinations, whereas those who are more focused on social life and self-expression will spend more time on leisure and cultural activities. Consequently, differences in the proportion of activities may contribute to various wellbeing domains. In addition, some socioeconomic characteristics are found to be moderators of environment-wellbeing associations (Perez et al., 2018). For example, according to some studies, the risk of travel-related social exclusion is higher among certain social groups, such as older adults, people with disabilities, single parents, and disadvantaged immigrants (Kenyon et al., 2002). Furthermore, different types of households may display different travel patterns in similar neighborhoods. A study from Melbourne shows that wealthy households with cars have larger ASs and are more sensitive to accessibility issues than less affluent and car-less households (Manaugh \& El-Geneidy, 2012).

Despite the predominant focus of literature on the geometric characteristics of activity spaces, there are evidences showing that these may not fully capture all the associations (Kamruzzaman \& Hine, 2012). It may be necessary to include other measures of travel behavior, such as the number and diversity of activity types, visited places, and trips. For instance, researchers have theorized that the number of unique visited locations is an indication of social involvement (Schönfelder \& Axhausen, 2003). The composition of activity types may also provide relevant information on lifestyle expression, for instance an emphasis on mandatory (e.g., work- or family-related) or discretionary travel (e.g., for leisure purposes).

\section{$3 \quad$ Materials and methods}

\subsection{SoftGIS survey and data collection}

The data was collected using softGIS, in which data on individual activities and experiences is collected via online mapping surveys (or geo-questionnaires) that allow respondents to draw, mark, or select geographical features on interactive maps and answer contextual questions pertaining to these features (Czepkiewicz, Jankowski, \& Młodkowski, 2016; Kahila \& Kyttä, 2009). The softGIS methodology has been used in a variety of research domains, including transportation (Haybatollahi, Czepkiewicz, Laatikainen, \& Kyttä, 2015; Salonen, Broberg, Kyttä, \& Toivonen, 2014; Sarjala, Broberg, \& Hynynen, 2015).

We targeted the data collection at inhabitants of the Helsinki metropolitan area (HMA; consisting of the municipalities of Helsinki, Vantaa, Kauniainen, and Espoo) aged 25 to 40 years. The choice of the age group was done for three reasons. First, people in this age group share certain life-cycle characteristics, meaning they predominantly belong to the active workforce and are independent adults who no longer live with their parents and are well before retirement age. Second, people of this age constitute a generation that has grown up in a globalized world with access to information and communication technologies. Third, understanding young adults' lifestyles is especially relevant for planning sustainable built environments for the future. 
The Population Register Center of Finland provided addresses for a random sample of the target population. In August 2016, we contacted 5,000 individuals by letter and asked them to use the Internet to answer the questionnaire. In September 2016, we sent out a second round of invitations. A total 962 people responded to the questionnaire, 866 of whom provided location data on their home and workplace, thus constituting the final sample for analysis. The final response rate was $17.69 \%$. This is a satisfactory response rate compared to the average response rate of 13\% for Internet-based PPGIS studies reported by Brown and Kyttä (2014).

The questionnaire included twelve pages, with two pages featuring questions related to daily travel patterns. On one of the pages, respondents provided the locations and attributes of their homes as well as their work or study places. Subsequently, respondents were asked to mark between 5 and 15 locations and provide characteristics of the places they frequently visit within the HMA ("Please mark locations that you frequently visit within the Helsinki metropolitan area"). Participants placed the locations in six categories: services and errands; shopping; leisure and going out; culture and sport events; daycare, kindergarten, or school; sports and active recreation. Each marked location was associated with attribute data on travel mode, frequency of visits, and direction of travel (i.e., whether it is typically visited from home, work, or study place, or on the way between home and work/study place). Trip frequencies were measured as answers to the question "How often do you usually visit this place?" in categories related to weekly and monthly periods (e.g., "five to seven times a week" or "once or twice a month").

Wellbeing was measured using the ten following statements referring to satisfaction with life domains and with life in general, presented as a continuation of the "How satisfied are you with..." phrase:

- your material standard of living?

- your current state of health?

- your personal relationships?

- feeling part of your community?

- the amount of time you have to do the things you like doing?

- your main occupation, such as job or studies?

- the quality of your local environment?

- things you are achieving in life?

- how safe you feel?

- your life as a whole these days?

Responses were formatted on an 11-step scale, ranging from 0 to 10, where zero meant "not at all satisfied" and 10 meant "completely satisfied". The list of statements was based on the "Domain evaluation" module from the OECD's Guidelines on Measuring Subjective Wellbeing (OECD, 2013) and modified to suit the research questions and target group of the study. The OECD scale was based on the Personal Wellbeing Index (PWI, International Wellbeing Group, 2013) and opinion surveys used by the British Office for National Statistics. The modifications for the present study involved modifications in the wording of four items after the pilot interviews, excluding one item ("How satisfied are you with your future security?"), and adding an item on general life satisfaction ("How satisfied are you with your life as a whole these days?"). The module allowed us to collect respondents' evaluative judgments on various aspects of their lives.

\subsection{Study area and urban zone data}

To study the relationships between urban form and ASs, we used the travel-related urban zone classification system provided by the Finnish Environment Institute. It is a GIS-based (250 x $250 \mathrm{~m}$ grid of cells) system that divides urban regions into zones according to their locations in the urban form (e.g., in relation to the center) and travel-relevant variables, such as population characteristics, public trans- 
port supply, building stock, and jobs (Söderström, Schulman, \& Ristimäki, 2015). The classification system is closely linked with the model for Three Urban Fabrics by Newman, Kosonen, \& Kenworthy (2016). For the purposes of this article, we divided the information into six zones: car zone, basic public transport zone, Intensive public transport zone, pedestrian zones of the sub-centers, fringe of the central pedestrian zone, and central pedestrian zone (figure 2). For each respondent, we assigned the urban zone of their residential location.

The central pedestrian zone and its fringe constitute a densely-built and walkable center of the HMA, with a high number of jobs and services and good access to public transportation. Pedestrian zones of the sub-centers are located around the main railway stations and commercial centers, and they host a diversity of housing, jobs, and services. Together with the intensive public transport zone, they constitute corridors with good access to public transportation. The basic public transportation zone and car zone are located farther from public transportation connections, are closer to the urban fringe, and have a lower population density and access to jobs and services (Söderström et al., 2015).

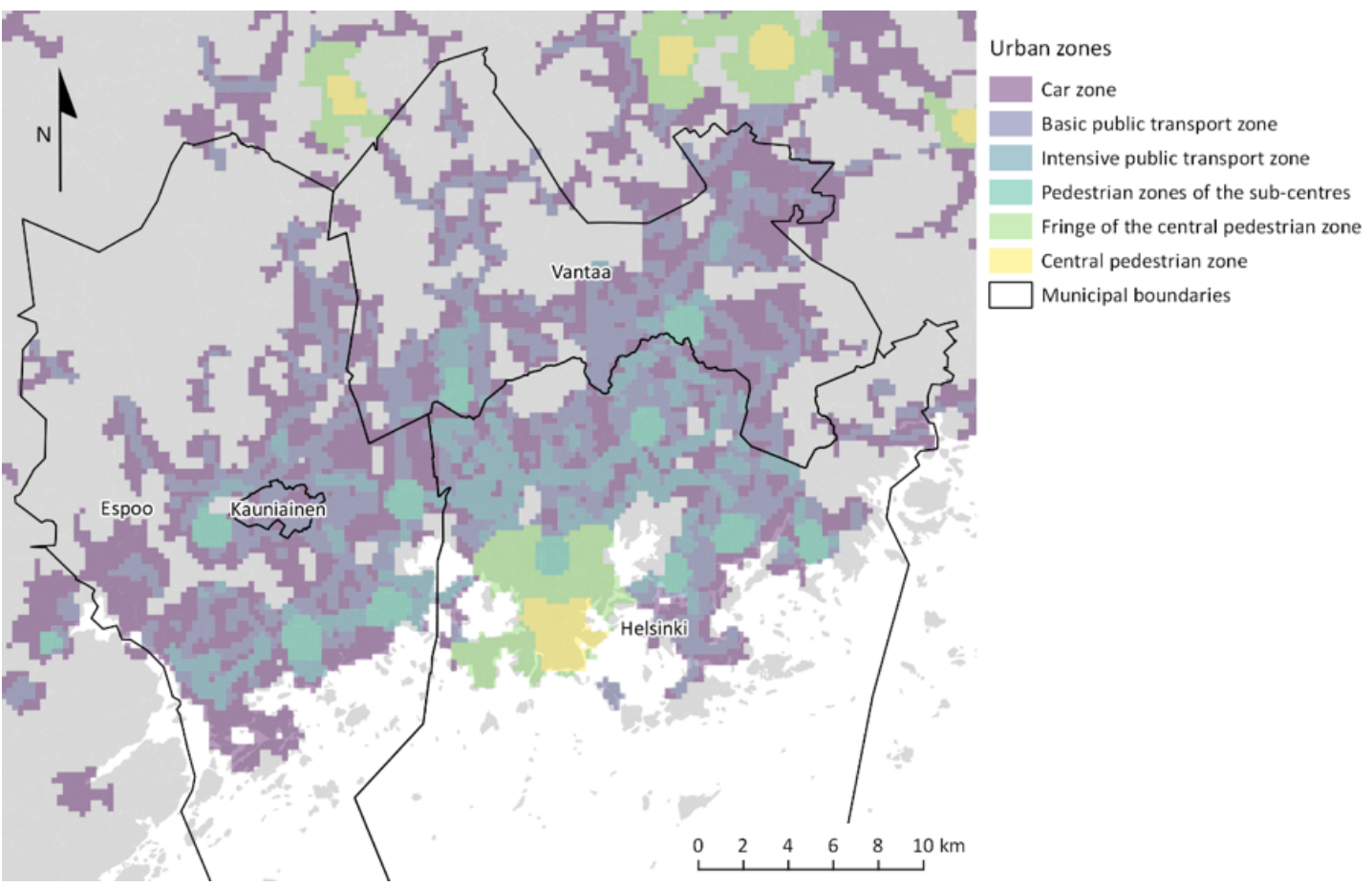

Figure 2. The location of Helsinki Metropolitan Area and its division into travel-related urban-zones. The study area includes only terrestrial part of the region.

\subsection{Activity space measurement and modeling}

Table 1 presents a complete list of 33 variables that we measured for the dataset as well as a short description of how they were calculated. These variables were chosen to provide insights into different AS aspects. In the process of selecting the variables, we first identified the five main hypothetical dimensions of AS measurement based on Perchoux et al. (2014), and then strove to represent each of the dimensions with a balanced set of variables derived from both earlier studies and our own additions. In the case of previously used variables, references are provided in the table. It is noteworthy that in choosing the variables, we tried to avoid measures that are overly sensitive towards outliers or rely too much on arbitrary choices and assumptions. Figure 3 provides a visual example of some of the AS measures employed in this study. 
Table 1. Variables describing characteristics of individual ASs

\begin{tabular}{|c|c|c|}
\hline Measured variable & Measurement method (interpretation) & References \\
\hline \multicolumn{3}{|c|}{ Measures related to activities } \\
\hline $\begin{array}{l}\text { Number of activity } \\
\text { locations }\end{array}$ & $\begin{array}{l}\text { Arcpy script: Counting number of activity locations } \\
\text { made by the participant }\end{array}$ & $\begin{array}{l}\text { (Buliung, Roorda, \& Remmel, 2008; } \\
\text { Dijst, 1999; Perchoux et al., 2014; } \\
\text { Schönfelder \& Axhausen, 2002b, } \\
\text { 2003) }\end{array}$ \\
\hline Number of activity types & $\begin{array}{l}\text { Arcpy script: counting distinct activity types (six } \\
\text { categories: services and errands; shopping; leisure } \\
\text { and going out; culture and sport events; daycare, } \\
\text { kindergarten or school; sports and active recreation) }\end{array}$ & $\begin{array}{l}\text { (Buliung et al., 2008; Hasanzadeh, } \\
\text { Laatikainen, \& Kyttä, 2018; Per- } \\
\text { choux et al., 2014; Rai et al., 2007) }\end{array}$ \\
\hline $\begin{array}{l}\text { Share of activity locations of } \\
\text { different type }\end{array}$ & $\begin{array}{l}\text { Ratio of activity locations from each of the cat- } \\
\text { egories: cultural, leisure, work or study, children- } \\
\text { related, sport, shopping and services; weighted by } \\
\text { frequency of visits. } \\
\text { (this can indicate the relevant importance of each } \\
\text { activity type in mobility behavior) }\end{array}$ & \\
\hline Total frequency of visits & $\begin{array}{l}\text { Arcpy script: calculating the total estimated number } \\
\text { of visits to all activity locations }\end{array}$ & $\begin{array}{l}\text { (Buliung et al., 2008; Perchoux et } \\
\text { al., 2014; Schönfelder \& Axhausen, } \\
\text { 2004; Schönfelder \& Axhausen, } \\
\text { 2002a, 2003) }\end{array}$ \\
\hline $\begin{array}{l}\text { Share of activity locations } \\
\text { visited using different } \\
\text { transportation modes }\end{array}$ & $\begin{array}{l}\text { Ratio of number of activity locations visited using } \\
\text { active transportation modes (on foot or by bicycle), } \\
\text { car, and public transportation (bus or rail) to the } \\
\text { total number of activity locations; weighted by } \\
\text { frequency of visits. } \\
\text { (this can indicate the relevant importance of each } \\
\text { travel mode in mobility behavior) }\end{array}$ & \\
\hline
\end{tabular}

Number of individual activity centers

Percent of activity locations inside home range

Unweighted distance

between $\mathrm{C} 1$ and $\mathrm{C} 2$
Arcpy script: counting number of activity centers (spatial clusters containing activity locations within $1000 \mathrm{~m}$ distance from each other)

(Hasanzadeh, 2019)

(this indicates the polycentricity of ASs)

Arcpy script: percentage of activity locations within $2800 \mathrm{~m}$ distance from the domicile. The distance threshold was determined based on distances between domiciles and activity locations using Jenks optimization method of natural break identification (Hasanzadeh, 2018; Hasanzadeh et al., 2017).

(a higher percentage of activities located within neighborhood indicates a higher concentration of travel around domicile)

Arcpy script: Euclidean distance between the centroids of the first (C1) and second (C2) most frequently visited activity centers

(A higher value for this measure can be interpreted as a higher level of dispersion between activity centers)
(Hasanzadeh et al., 2018; Perchoux et al., 2014) 
Weighted distance between

$\mathrm{C} 1$ and $\mathrm{C} 2$

SDE eccentricity

SDE elongation

Volume of activities inside SDE

Distance between SDE center and home

Gravelius index of MCP

Minimum, maximum, and average Euclidean distance to activity locations

Average and total network distance to activity locations

SDE size

Arcpy script: Euclidean distance between the centroids of the first (C1) and second (C2) most frequently visited activity clusters, weighted by the frequency of visits at two ends

(A higher value for this measure can be interpreted as a higher level of dispersion between activity centers)

ArcGIS: Ratio of the distance between the domicile and the SDE centroid to the length of major ellipse axis

(A higher value for this measure can be interpreted as a higher level of dispersion between activity places and domicile)

ArcGIS: Ratio of major to minor axis of the SDE (A high value for this measure is an indicator of SDE's elongation in shape. A low value for this measure can be interpreted as omnidirectional dispersion in travel behavior)

ArcGIS: Ratio of the number of activity locations to the shape area of standard deviational ellipse $\left({ }^{*} 10^{6}\right)$ (this can be interpreted as the spatial density of activity points across AS)

Arcpy script: Euclidian distance between domicile and SDE centroid

(A higher value for this measure can be interpreted as a higher level of dispersion between activity places and domicile)

ArcGIS: Gravelius index of maximum convex polygon. $\mathrm{K}=\mathrm{P} /(2 \sqrt{ } \mathrm{A} \mathrm{A})$ (where $\mathrm{P}$ and $\mathrm{A}$ are the perimeter and area of the MCP respectively) (This is a compactness measure. Thus, it can be interpreted similar to elongation)

Arcpy script: minimum, maximum, and average Euclidean distance from domicile to activity locations

ArcGIS Network Analyst: average and sum of shortest path distances along road network between domicile and activity locations Measures of activity space size ArcGIS Directional Distribution: Area of Standard Deviational Ellipse (one standard deviation) of activity locations \(A higher value for this measure indicates a bigger area of activity space )
(Perchoux et al., 2014)

(Lord, Joerin, \& Thériault, 2009;

Newsome, Walcott, \& Smith, 1998;

Perchoux et al., 2014)

(Perchoux et al., 2014)

(Perchoux et al., 2014)

(Perchoux et al., 2014)
(Flamm \& Kaufmann, 2006;

Sherman et al., 2005) 
Area of MCP

Perimeter of MCP
Arcpy script: Area of the minimum convex polygon

(MCP) encompassing all activity points marked by the individual

(Perchoux et al., 2014)

(A higher value for this measure indicates a bigger area of activity space )

Arcpy script: Perimeter of the MCP encompassing all activity points marked by the individual

(A higher value for this measure may imply a bigger area of activity space-however accurate interpretation of this measure needs to be done together with area or measure of compactness)

Further, it should be noted that the network distances were calculated using Digiroad, a road dataset provided by Finnish Transport Agency, which includes all motorway and pedestrian routes in Finland. For each marked location, we calculated the distance from residential location and work or study place. We used a shortest path algorithm in the Network Analyst toolbox in ArcGIS Desktop 10.

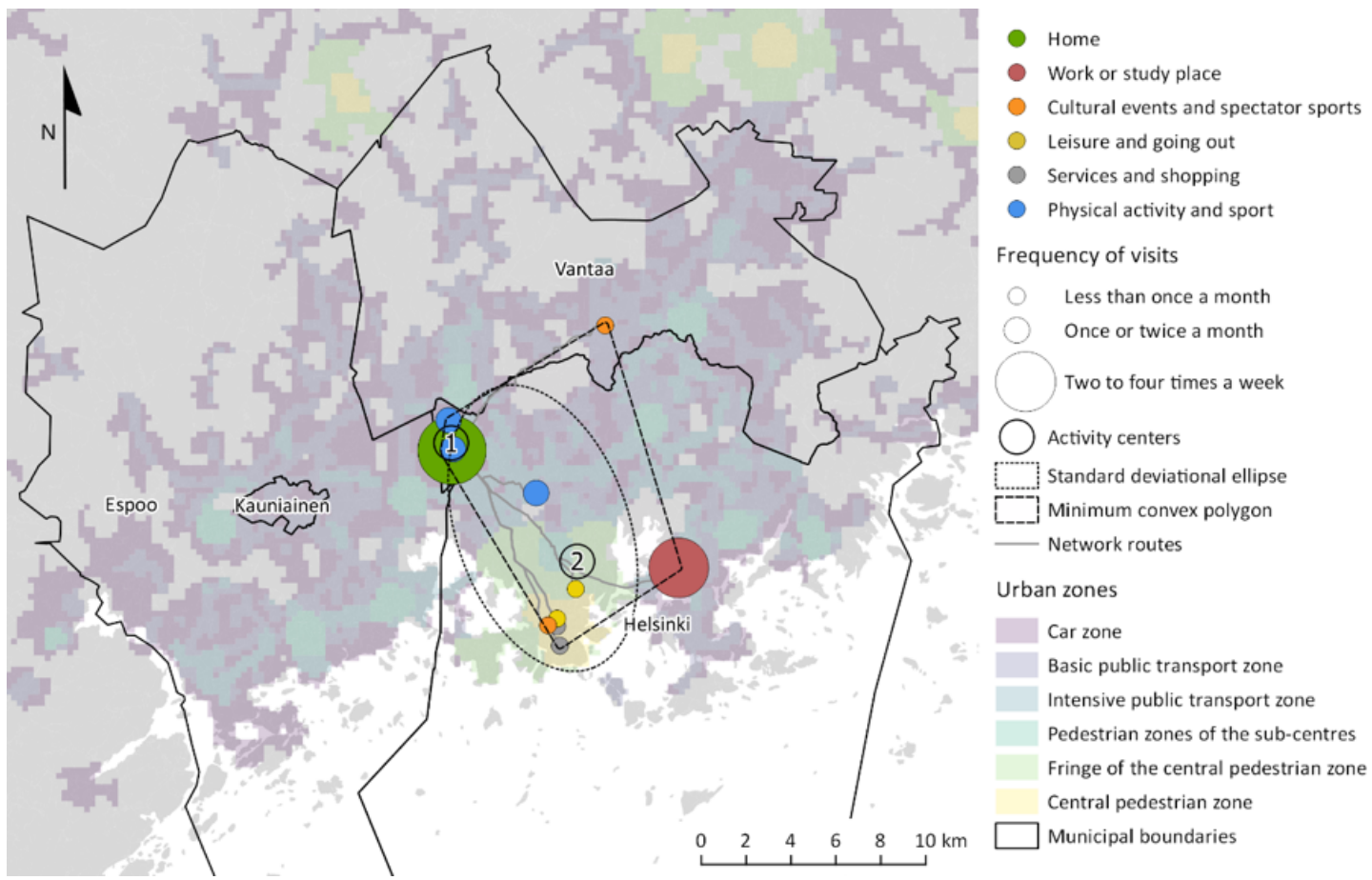

Figure 3. Exemplary AS of a participant and its location within HMA

\subsection{Statistical analysis}

In order to identify the main dimensions of spatial behavior and AS characteristics, we performed a principal component analysis (PCA) on the 30 numeric variables (all variables presented in table 1 except travel modes), using a varimax rotation. The three transportation mode variables had different distributions than the other variables, and therefore, were left out of the PCA to prevent biased estima- 
tion. A seven-component solution was selected based on Eigen values greater than 1.3, and scores were estimated using the Anderson-Rubin method (Scree plot in appendix 1). By using PCA, we identify the main signal in the data by reducing the effect of outliers and the number of dimensions (Hwang, Montréal, Dillon, \& Takane, 2006; Rai \& Daumé, n.d.). This can in turn improve the quality of the subsequent clustering analysis and facilitate its interpretation. This is a valid approach since the PCA maintains more than $70 \%$ of the total variance in the data (Lebart, Morineau, $\&$ Piron, 2000).

Following the reduction of dimensions, a k-means clustering analysis was conducted to identify different types of ASs, exhibiting different daily mobility patterns. The analysis was performed on the seven identified components together with the three remaining variables indicating the transportation modes. Using Log-likelihood as the distance measure and Akaike's information criterion, three clusters were identified. The means of the clusters for each dimension were compared and tested for significance using one-way ANOVA. We then described the clusters in terms of the socio-demographic characteristics of their members and location of their homes and workplaces in the urban region. The significance of the socio-demographic differences between AS types were tested using a two-proportion z-test by way of comparing the value of a given cluster with the rest of the sample (i.e., two remaining clusters), with the null hypothesis stating that the values are identical.

Further, associations between wellbeing measures and mobility characteristics were identified using linear regression analysis. The regression results were controlled for four socio-demographic variables, namely age, income, gender, and education. Residuals of the regression models were tested for spatial autocorrelation with Moran's I statistic. We also tested the significance of differences in wellbeing measures between the AS clusters. Due to the non-normal distribution of the wellbeing factors, a non-parametric test, namely the Kruskal-Wallis $\mathrm{H}$ test, was used to evaluate the significance of between-group differences.

\section{$4 \quad$ Results}

We identified seven components of AS characteristics: size, volume of travel distances, intensity of activities, exteriority, polycentricity, elongation, and leisure specialization. The intensity of activities was positively related to several domains of life satisfaction, most strongly to satisfaction with the quality of local environment, and to satisfaction with life as a whole, after controlling for main sociodemographic variables. Exteriority was negatively related to satisfaction with job or studies, safety, and life as a whole. The components, together with the variables describing the share of travel modes used by individuals, allowed us to identify three distinct classes of activity spaces. The three clusters differed considerably in terms of the socio-demographic characteristics and perceived well-being of their members. In the following sections, we will present the results in more detail. 


\subsection{Principal component analysis of measures of mobility behavior}

The PCA results are presented in table 2. We retained seven components, which explained $70 \%$ of variance.

Table 2. Factor analysis of measures of mobility behavior $(n=866)$

\begin{tabular}{|c|c|c|c|c|c|c|c|}
\hline $\begin{array}{l}\% \text { of variance } \\
\text { explained }\end{array}$ & $22 \%$ & $\begin{array}{l}\text { Volume of } \\
\text { travel distances } \\
13 \%\end{array}$ & $\begin{array}{l}\text { Intensity } \\
\text { of activities } \\
11 \%\end{array}$ & $7 \%$ & $\begin{array}{l}\text { Polycentricity } \\
6 \%\end{array}$ & $\begin{array}{l}\text { Elongation } \\
6 \%\end{array}$ & $\begin{array}{l}\text { Leisure } \\
\text { specialization } \\
5 \%\end{array}$ \\
\hline Area of MCP & $.951^{*}$ & - & - & - & - & - & - \\
\hline Perimeter of MCP & $.967^{*}$ & - & - & - & - & - & - \\
\hline $\begin{array}{l}\text { Gravelius index of } \\
\text { convex hull }\end{array}$ & - & $.850^{*}$ & - & .250 & - & - & - \\
\hline SDE size & $.985^{*}$ & - & - & - & - & - & - \\
\hline $\begin{array}{l}\text { Distance between } \\
\text { SDE center and } \\
\text { home }\end{array}$ & $.645^{*}$ & - & - & $.691^{*}$ & - & - & - \\
\hline SDE eccentricity & - & - & - & .337 & .422 & - & .321 \\
\hline SDE elongation & - & - & - & - & - & $.842^{*}$ & - \\
\hline $\begin{array}{l}\text { Frequency of activi- } \\
\text { ties inside SDE }\end{array}$ & - & - & - & - & - & $.858^{*}$ & - \\
\hline $\begin{array}{l}\text { Number of activity } \\
\text { centers }\end{array}$ & - & - & .488 & - & $.631^{*}$ & - & - \\
\hline $\begin{array}{l}\text { Unweighted distance } \\
\text { between } \mathrm{C} 1 \text { and } \mathrm{C} 2\end{array}$ & - & $.886^{*}$ & - & .358 & - & - & - \\
\hline $\begin{array}{l}\text { Weighted distance } \\
\text { between C1 and C2 }\end{array}$ & - & $.619^{*}$ & - & - & - & - & - \\
\hline $\begin{array}{l}\text { Percentage of } \\
\text { activities inside home } \\
\text { neighborhood }\end{array}$ & - & - & - & - & $-.789^{*}$ & - & - \\
\hline $\begin{array}{l}\text { Number of activity } \\
\text { types }\end{array}$ & - & - & $.818^{*}$ & - & - & - & - \\
\hline $\begin{array}{l}\text { Total frequency of } \\
\text { visits }\end{array}$ & - & - & $.807^{*}$ & - & - & - & - \\
\hline $\begin{array}{l}\text { Number of activity } \\
\text { locations }\end{array}$ & - & - & $.771^{*}$ & - & - & - & - \\
\hline $\begin{array}{l}\text { Minimum Euclidean } \\
\text { distance to activity } \\
\text { location }\end{array}$ & - & - & - & $.874^{*}$ & - & - & - \\
\hline $\begin{array}{l}\text { Maximum Euclidean } \\
\text { distance to activity } \\
\text { location }\end{array}$ & $.963^{*}$ & - & - & - & - & - & - \\
\hline $\begin{array}{l}\text { Average Euclidean } \\
\text { distance to activity } \\
\text { location }\end{array}$ & .484 & $.667^{*}$ & - & .521 & - & - & - \\
\hline
\end{tabular}




\begin{tabular}{|c|c|c|c|c|c|c|c|}
\hline $\begin{array}{l}\text { Average network } \\
\text { distance to activity } \\
\text { location }\end{array}$ & - & $.874^{*}$ & - & - & - & - & - \\
\hline $\begin{array}{l}\text { Total network } \\
\text { distance to activity } \\
\text { locations }\end{array}$ & - & $.790^{*}$ & .282 & - & .278 & - & - \\
\hline $\begin{array}{l}\text { Share of cultural } \\
\text { activity locations }\end{array}$ & - & - & - & - & - & - & .416 \\
\hline $\begin{array}{l}\text { Share of childcare } \\
\text { activity locations }\end{array}$ & - & - & .451 & - & - & - & -.538 \\
\hline $\begin{array}{l}\text { Share of leisure } \\
\text { activity locations }\end{array}$ & - & - & - & - & - & - & .445 \\
\hline $\begin{array}{l}\text { Share of sport activity } \\
\text { locations }\end{array}$ & - & - & - & - & - & - & $.601^{*}$ \\
\hline $\begin{array}{l}\text { Share of work or } \\
\text { study activity } \\
\text { locations }\end{array}$ & - & - & -.485 & - & .456 & - & -.526 \\
\hline $\begin{array}{l}\text { Share of shop and } \\
\text { service activity }\end{array}$ & - & - & - & - & -.407 & - & - \\
\hline
\end{tabular}

Factor loadings higher than .6 are flagged with*. Values lower than .25 are not reported.

The first component, size, is self-explanatory, as it indicates the overall size of an individual AS. The second component, volume of travel distances, is largely influenced by different travel distance measurements and is best indicative of the overall distances traveled by individuals. The third component, intensity of activities, is largely influenced by measures determining the overall frequency, number, and types of activities and visited destinations. While influenced by various variables, the fourth component, exteriority, shows the extent to which an individual's activity locations are concentrated outside their home range. For example, a person with a high value for exteriority has reported a larger share of activities outside his or her home range. While sharing similarities, this is different from the elongation component. Elongation is based on the geometrical properties of AS and is not influenced by the distance between activity locations and one's domicile, and its high values signify that an individual travels predominantly in one direction from home. Polycentricity is positively influenced by the number of activity centers and negatively influenced by the share of activities conducted outside one's home range. Persons with a high value for polycentricity thus have more activity centers than their immediate home surrounding. Finally, leisure specialization is largely influenced by the shares of different activity types. Individuals with a high score are more often engaged in leisure, cultural, or sport activities, while individuals with a low score travel are more often engaged in activities related to work, study, or childcare.

Most of the individual measures loaded to the components as expected. For instance, different measurements for AS area and perimeter contributed to the component size. Similarly, various kinds of travel distance measures contributed to the volume of travel distances. Variables related to shares of activity types loaded to the leisure specialization component. Similar to previous studies (Perchoux et al., 2014), activity type variables did not correlate with the geometrical characteristics. This suggests a lack of association between activity participation and mobility, which requires further investigation. 
However, share of childcare activities positively correlated with variables indicating the frequency and intensity of activities and negatively correlated with the share of leisure activities. On the other hand, the share of work or study activities negatively correlated with intensity of activities and positively correlated with polycentricity. This suggests that people who commute to multiple locations, as well as those who have a high share of childcare-related activities, tend to engage in less discretionary travel (e.g., for leisure activities).

\subsection{Clustering analysis}

We used k-means clustering analysis on ten variables and identified four clusters. One of the clusters, which only included eight participants, was regarded as an outlier class and was therefore left out of the study. The three valid clusters included 353, 300, and 199 participants, or $41 \%, 35 \%$, and $23 \%$ of participants, respectively. The results from one-way ANOVA show (presented in appendix 2) that all components except exteriority and size have significantly contributed to the clusters' specification. Despite the statistically significant contribution of the five AS dimensions to the clustering, the three travel modes were the most influential factors in the analysis. This indicates the importance of these factors in explaining the daily mobility patterns of individuals and the relative independence between travel modes and other AS characteristics. Figure 4 illustrates the average values of variables in each cluster, and table 3 presents the socio-demographic characteristics of each of these clusters.

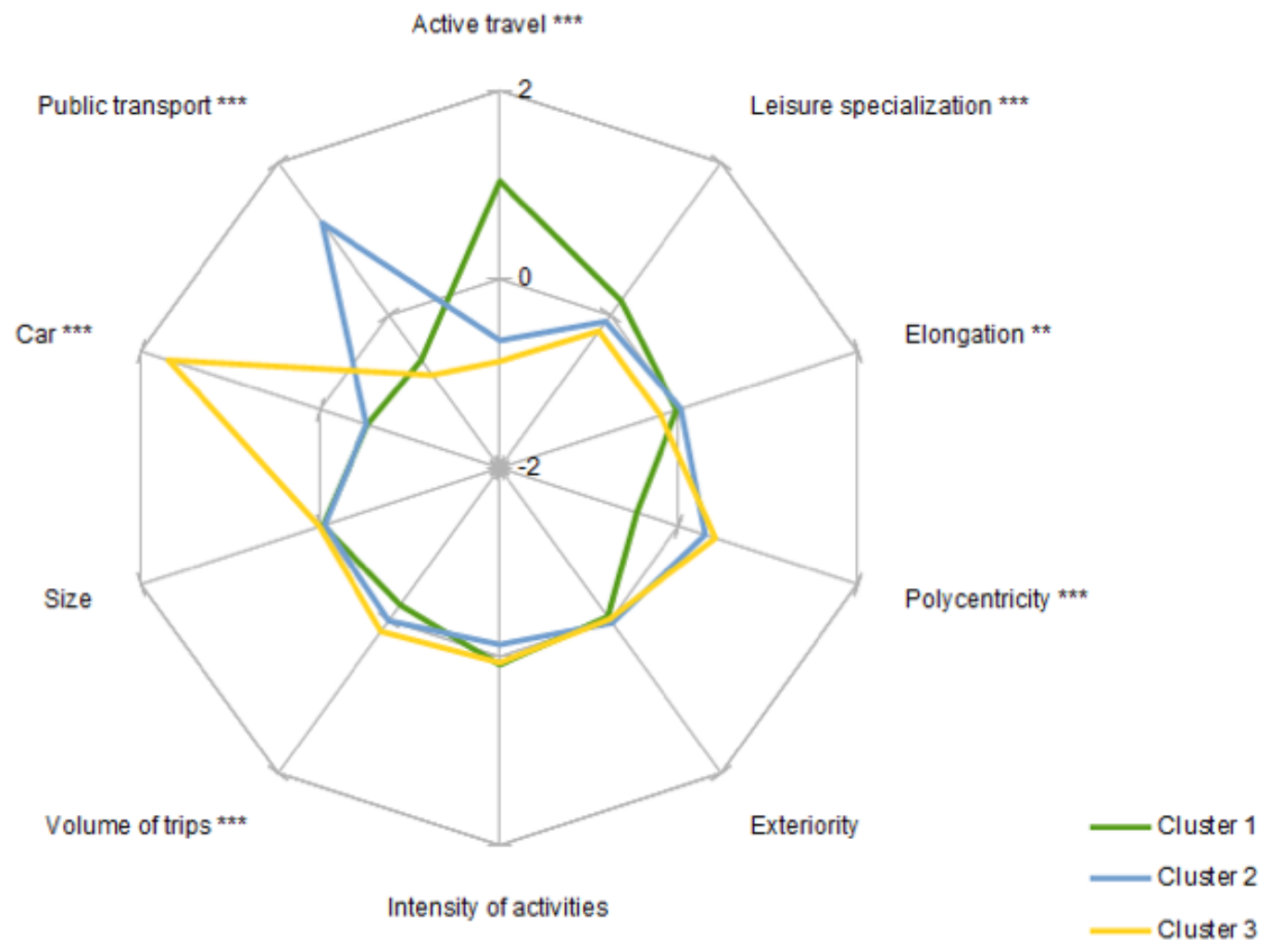

Figure 4. Average standardized values of variables used for clustering in each of the clusters. Significance symbols ${ }^{* * *} \mathrm{p}<0.001$, ${ }^{* *} \mathrm{p}<0.01,{ }^{*} \mathrm{p}<0.05$ 
Members of cluster 1 (those with home-centered active travel-oriented ASs) reported the lowest use of a car as their transportation mode, while ranking highest in the use of active transportation modes (walking, cycling). Compared to other groups, their activities included less work- and childcare-related activities, and more leisure and cultural activities. Their activities mostly centered around their homes and rarely clustered around several centers. Members of this cluster were similar in age, gender, household composition, and income to the rest of the sample. They reportedly were less often employed and more often stay-at-home parents or unemployed. Their education level was only slightly higher than that of the rest of the sample, and their percentage of car ownership was less than that of the rest of the sample. They less often live in a suburban car zone and basic public transport zone, and more often live in a central pedestrian zone and its fringe.

Individuals in cluster 2 (those with Public transportation-oriented ASs) scored highest in public transportation modes. They reported traveling longer distances than members of cluster 1, but travel less frequently. They engaged in a mixed range of activity types and their activity spaces were most elongated compared to those from the other two clusters. Their activities were more often clustered around several locations. Compared to the rest of the sample, members of this cluster were generally younger. The cluster included a smaller share of couples with children and a larger share of students. They reported markedly lower incomes than the rest of the sample and less frequent use of a car. Their spatial distribution was similar to that of the general sample, except that they less often lived in the central pedestrian zone.

Members of cluster 3 (those with Polycentric car-oriented ASs) scored highest in terms of work and childcare-related activities. They most commonly used a car and least often used active travel and public transportation compared to the rest of the sample. Their activity spaces were most polycentric and had the highest volume of travel distances. Members of this cluster were, on average, somewhat older and more typically included couples with children. There were less women and more men in this group, and their income was higher than in the other clusters. The cluster included higher numbers of employed people and lower numbers of students or unemployed persons. On average, members of this cluster reported spending more time working than the rest of the sample. Almost all of them (99\%) had at least one car in the household, and $31 \%$ had two or more cars. More of them inhabited the suburban car zone and basic public transport zone, while fewer inhabited the central pedestrian zone and its fringe.

Table 3. Socio-demographic characteristics of the three identified clusters. Significance symbols ${ }^{* * *} \mathrm{p}<0.001{ }^{* *} \mathrm{p}<0.01$, * $\mathrm{p}<0.05$

\begin{tabular}{lllll} 
& Cluster 1 & Cluster 2 & Cluster 3 & Sample \\
\hline Age group & & & & \\
$25-28$ & $24 \%$ & $35 \%^{* * *}$ & $20 \%^{*}$ & $27 \%$ \\
$29-32$ & $23 \%$ & $22 \%$ & $20 \%$ & $22 \%$ \\
$33-36$ & $26 \%$ & $24 \%$ & $26 \%$ & $25 \%$ \\
$37-41$ & $27 \%$ & $19 \%^{* * *}$ & $35 \%^{* *}$ & $26 \%$ \\
\hline Household & & & \\
Couple living together & $33 \%$ & $37 \%$ & $28 \%$ & $33 \%$ \\
Couple with child/children & $33 \%$ & $24 \%{ }^{* * *}$ & $43 \%{ }^{* * *}$ & $32 \%$ \\
Single person living on her or his own & $25 \%$ & $27 \%$ & $19 \%$ & $25 \%$ \\
\hline Gender & & & & $5 \%$ \\
Female & $61 \%$ & $63 \%$ & $48 \%{ }^{* * *}$ & $59 \%$ \\
Male & $39 \%$ & $37 \%$ & $52 \%{ }^{* *}$ & $41 \%$ \\
\hline
\end{tabular}




\begin{tabular}{|c|c|c|c|c|}
\hline \multicolumn{5}{|l|}{ Income } \\
\hline less than 3000 EUR & $39 \% *$ & $41 \% * *$ & $14 \% * * *$ & $34 \%$ \\
\hline $3000-6500$ EUR & $43 \%$ & $45 \%$ & $52 \%$ & $46 \%$ \\
\hline more than 6500 EUR & $18 \%$ & $15 \% * *$ & $34 \% * * *$ & $20 \%$ \\
\hline \multicolumn{5}{|l|}{ Education } \\
\hline Upper secondary & $14 \%$ & $16 \%$ & $20 \%$ & $17 \%$ \\
\hline Undergraduate & $29 \%$ & $32 \%$ & $28 \%$ & $30 \%$ \\
\hline Graduate & $43 \%$ & $40 \%$ & $37 \%$ & $40 \%$ \\
\hline Postgraduate & $7 \% *$ & $3 \%$ & $3 \%$ & $4 \%$ \\
\hline \multicolumn{5}{|l|}{ Occupation } \\
\hline Employed & $68 \% * * *$ & $71 \%$ & $89 \%$ *** & $74 \%$ \\
\hline Stay-at-home parent & $8 \% *$ & $5 \%$ & $5 \%$ & $6 \%$ \\
\hline Student & $13 \%$ & $17 \% * *$ & $4 \% * * *$ & $12 \%$ \\
\hline Unemployed & $8 \%$ ** & $4 \%$ & $1 \% * *$ & $5 \%$ \\
\hline \multicolumn{5}{|l|}{ Hours worked } \\
\hline less than 30 & $19 \% * * *$ & $12 \%$ & $6 \% * * *$ & $14 \%$ \\
\hline 30 to 35 & $11 \%$ & $11 \%$ & $10 \%$ & $11 \%$ \\
\hline 35 to 40 & $42 \%$ & $47 \%$ & $44 \%$ & $45 \%$ \\
\hline 40 to 45 & $18 \% *$ & $22 \%$ & $28 \% *$ & $21 \%$ \\
\hline more than 45 & $9 \%$ & $7 \%$ & $12 \%$ & $9 \%$ \\
\hline \multicolumn{5}{|l|}{ Cars in household } \\
\hline None & $56 \% * * *$ & $57 \% * * *$ & $1 \% * * *$ & $43 \%$ \\
\hline One & $40 \%{ }^{* *}$ & $38 \% * *$ & $68 \% * * *$ & $46 \%$ \\
\hline Two or more & $4 \% * * *$ & $5 \% * * *$ & $31 \%$ *** & $11 \%$ \\
\hline \multicolumn{5}{|l|}{ Urban zone } \\
\hline Car zone & $8 \%{ }^{* * *}$ & $15 \%$ & $25 \% * * *$ & $14 \%$ \\
\hline Basic public transport zone & $16 \% * * *$ & $20 \%$ & $35 \% * * *$ & $22 \%$ \\
\hline Intensive public transport zone & $17 \%$ & $22 \%$ & $20 \%$ & $19 \%$ \\
\hline Pedestrian zones of the sub-centers & $12 \%$ & $13 \%$ & $10 \%$ & $12 \%$ \\
\hline Fringe of the central pedestrian zone & $29 \% * * *$ & $23 \%$ & $6 \% * * *$ & $22 \%$ \\
\hline Central pedestrian zone & $18 \%{ }^{* * *}$ & $7 \% * *$ & $5 \% * *$ & $11 \%$ \\
\hline
\end{tabular}

\subsection{Wellbeing, mobility behavior characteristics, and AS types}

Table 4 presents the significant associations observed between wellbeing measures, AS components, and four socio-demographic control variables. Intensity of activity positively correlated with different aspects of satisfaction, including health. On the other hand, the exteriority of ASs were statistically significantly associated with lower levels of wellbeing and satisfaction. Residuals of the models were not clustered spatially, except for the model predicting satisfaction with material standard of living. This domain of life satisfaction was underpredicted in some areas inhabited predominantly by wealthy middle-class households. This suggests that our models did not include some relevant variables related to wealth, such as home ownership or amount of savings, which may cluster in these areas. 
Table 4. Regression results showing associations between wellbeing measures and AS components.

\begin{tabular}{|c|c|c|c|c|c|c|c|c|c|c|c|}
\hline \multirow[b]{2}{*}{$\begin{array}{l}\text { Wellbeing } \\
\text { measures }\end{array}$} & \multicolumn{7}{|c|}{ AS Characteristics } & \multicolumn{4}{|c|}{$\begin{array}{l}\text { Socio-demographic variables } \\
\text { (controlling) }\end{array}$} \\
\hline & Size & $\begin{array}{l}\text { Volume } \\
\text { of travel } \\
\text { distances }\end{array}$ & $\begin{array}{l}\text { Intensity of } \\
\text { activities }\end{array}$ & Exteriority & Polycentricity & Elongation & $\begin{array}{c}\text { Leisure } \\
\text { specialization }\end{array}$ & Age & Income & $\begin{array}{c}\text { Gender } \\
\text { (vs. female) }\end{array}$ & Education \\
\hline $\begin{array}{l}\text { Material standard } \\
\text { of living }\end{array}$ & - & - & - & - & - & - & - & & 0.44 & - & 0.13 \\
\hline Health & - & - & 1.09 & - & - & - & - & & 0.19 & - & 0.12 \\
\hline $\begin{array}{l}\text { Personal } \\
\text { relationships }\end{array}$ & - & - & 1.21 & - & - & - & - & - & 0.32 & - & - \\
\hline Community & - & - & 1.36 & - & - & - & - & - & 0.32 & -0.38 & - \\
\hline Leisure time & & - & - & - & - & - & 2.31 & - & 0.13 & - & - \\
\hline Job and studies & 0.05 & - & - & -3.86 & 1.33 & - & - & - & 0.27 & - & - \\
\hline $\begin{array}{l}\text { Quality of local } \\
\text { environment }\end{array}$ & - & - & 1.32 & - & - & - & - & - & - & - & - \\
\hline Life achievements & - & - & 1.08 & - & - & - & - & - & 0.29 & - & 0.10 \\
\hline Safety & - & - & - & -2.48 & - & - & - & - & 0.16 & 0.27 & 0.15 \\
\hline Life & 6.33 & - & 1.79 & - & - & - & - & - & 0.31 & - & \\
\hline $\begin{array}{l}\text { Average } \\
\text { satisfaction }\end{array}$ & - & - & 1.08 & -2.06 & - & - & - & - & 0.25 & - & - \\
\hline
\end{tabular}

Only significant coefficients at $\mathrm{p}<.05$ are shown. Coefficients significant at $\mathrm{p}<.01$ are bolded.

Note: The dependent variables are measured on Likert scale (0-10)

Note: The model fittings are tested with ANOVA. All reported models are significant at $\mathrm{p}<.01$

Figure 5 shows the mean rank differences between clusters in the wellbeing measures. The KruskalWallis $\mathrm{H}$ test showed that there are statistically significant differences between the three AS clusters in all wellbeing measures except satisfaction with personal relationships (test results in appendix 3). 


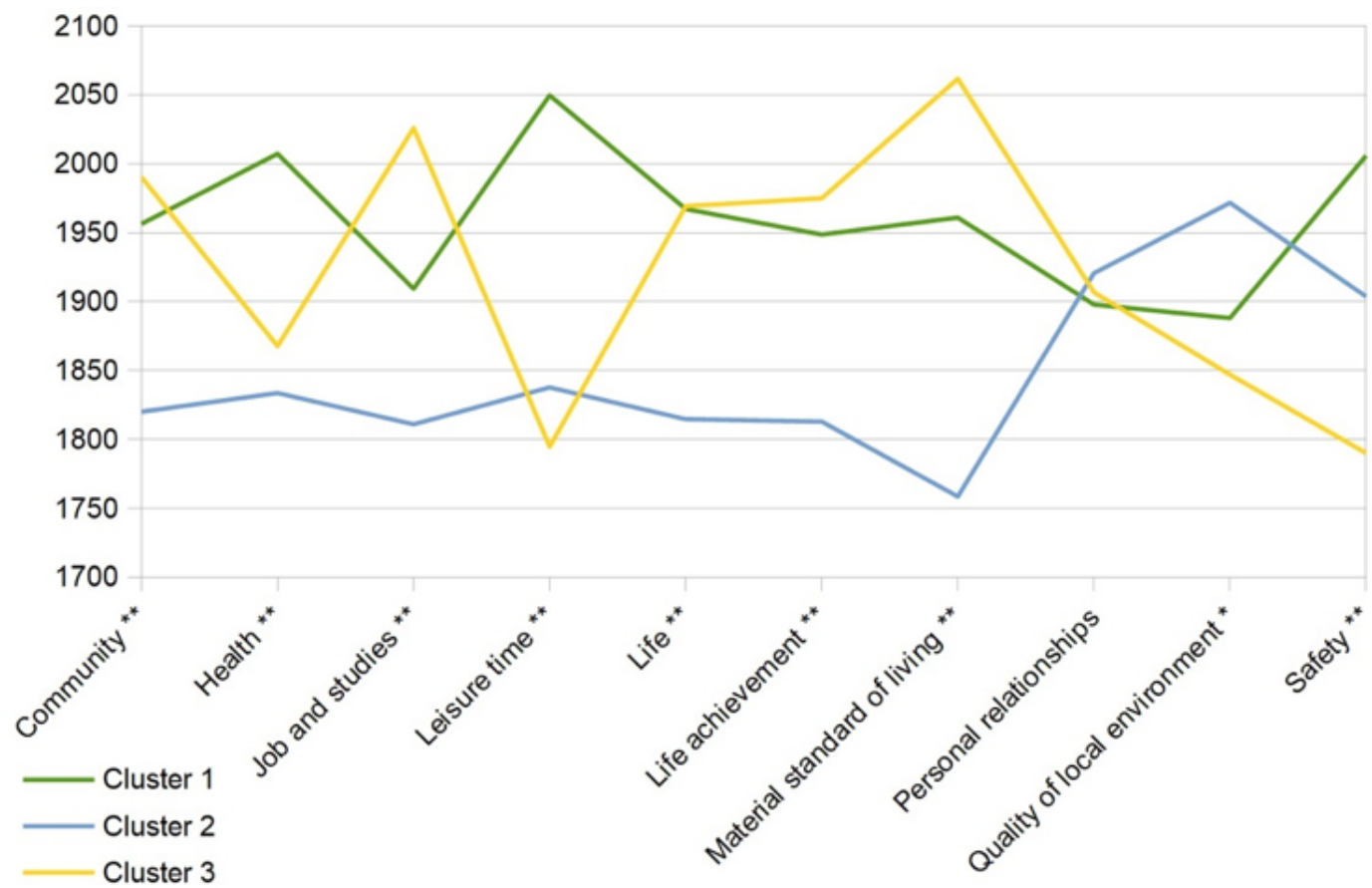

Figure 5. Mean rank differences on wellbeing measures by AS clusters.

Factors with statistically significant differences between clusters at $\mathrm{p}<.01$ and $\mathrm{p}<.05$ were marked by ${ }^{* *}$ and * respectively.

The differences in perceived wellbeing measures between AS types are in congruence with the mobility characteristics of each of these clusters. Individuals identified with home-centered active traveloriented ASs, appear to enjoy the highest level of perceived health, safety, and satisfaction with their leisure time. On the other hand, individuals identified with Polycentric car-oriented ASs, have low scores on their satisfaction with safety, quality of local environment, leisure time, health, and appear to be more satisfied with their occupation, life achievements, and material standard of living. Finally, individuals identified with Public transportation-oriented ASs, appear to have the lowest scores on most wellbeing measures with the exception of quality of local environment, for which they have scored as highest, and perceived safety.

\section{Discussion of results}

The PCA results supported our notion that activity space is a multidimensional construct. We identified seven distinct components: size, volume of travel distances, intensity of activities, exteriority, polycentricity, elongation, and leisure specialization. The results build upon previous efforts (Hasanzadeh et al., 2018; Perchoux et al., 2014; Sherman et al., 2005) and add to them by expanding the set of AS measures. First, thanks to variables describing the number and distribution of activity clusters, we could describe AS polycentricity beyond a focus on residential neighborhood. Second, adding activity clusters allowed us to identify volume of travel distances as a new component of AS measurement. This component is specifically valuable, as it is closely related to travel distances. Third, we identified exteriority as a new component, which then predicted differences in perceived wellbeing of study participants.

Our results differ from those of Perchoux et al. (2014) in the role of components for explaining variance. In their study, centering of AS on residential neighborhood explained $35 \%$ of variance, while the related components of polycentricity and exteriority in our study explained only $6 \%$ and $7 \%$ of the 
variance, respectively. This and other differences may result from using a different set of variables, but they may also be due to differences between study areas and the studied populations. The proposed measures and components can be used in future research, but any interpretation should be made according to the specific theme and geographic context of a study.

Further, we identified three distinct AS types: home-centered active-travel oriented, which are characterized by active travel modes, mostly concentrated within the home range of participants, and have high share of leisure, culture and sports-related activities; public transportation-oriented, which exhibit long travel distances to destinations dispersed across the region or clustered around several centers, covered mostly by means of public transportation; polycentric car-oriented, which rarely consist of active travel and often predominantly travel by car to work, study, shopping or service-related destinations clustered around multiple centers. Our observations indicate that transportation mode is a key dimension of activity space that goes beyond its geometric characteristics.

Our results indicate relationships between age, income, employment status, car ownership, and activity spaces, which are in line with reports from earlier studies (e.g., Buliung \& Kanaroglou, 2006; Flamm \& Kaufmann, 2006). There is also a clear relationship between the urban form of domicile and the AS type. Home-centered active-travel oriented ASs are more centrally located compared to the other two clusters. On the other hand, people with polycentric car-oriented ASs most commonly have their domiciles in outer suburban areas. Members of cluster two, public transportation-oriented ASs, have their homes scattered across the region, with a relatively smaller than perceived share of people living in very central areas. These relationships are congruent with well-established findings from earlier studies (Ewing \& Cervero, 2010; Naess, 2012).

As suggested in previous research, a small AS, concentrated around one daily center may be interpreted as a desirable outcome of planning ideals, such as a compact or walkable city (Manaugh \& El-Geneidy, 2012). It may also be an indicator of mobility deprivation (Meng, 2014) or social exclusion (Schönfelder \& Axhausen, 2003), both negative factors of wellbeing. In our results, AS size positively correlated with satisfaction with life in general and with one's main occupation. Contrary to Axhausen's hypothesis (2003), it is not apparently correlated with social wellbeing. Social integration is rather associated with the number and diversity of visited destinations, represented by the intensity of activities component, which correlated positively with satisfaction with life as a whole and satisfaction with being part of community. This suggests that among many aspects of daily travel behavior, visiting many diverse destinations not necessary located far from home may be one important factor of social wellbeing.

Conversely, we found negative correlations between multiple domains of wellbeing and AS exteriority. This AS component entails the majority of visited locations being far from home. It correlated negatively with satisfaction with job or studies, safety, and average satisfaction. The results suggest that traveling far from one's residential neighborhood to reach a job and other destinations, does not bring additional satisfaction. This may support findings on the negative effect of long commuting on life satisfaction (e.g., Stutzer \& Frey, 2008). Further, people with high exteriority tend to feel less safe in their local environment. The result may also suggest that people scoring high on exteriority inhabit neighborhoods that are poor in resources and are perceived less safe, thus the individuals are not able to meet their needs locally. Geographically, low values of exteriority cluster in central parts of Helsinki, which have good access to diverse services, and high values cluster in the outskirts. Based on the results, we could hypothesize that financial constraints combined with residing in an area poor in services, leads to inability to meet person's needs locally. This in turn leads to deprivation reflected in lower satisfaction with multiple life domains. This hypothesis could be verified by future studies.

Nevertheless, the volume of travel distances was not related to any of the wellbeing domains. This could be related to the way volume of travel was measured, assuming the place of domicile as the origin of all trips. This can be addressed in a future study using more accurate sources of geographical data such as GPS and mobile phone tracking. 
In line with our expectations, we found that the share of activities related to leisure, sport, and culture positively related to amount of available leisure time, but negatively related to satisfaction with one's material situation. However, when controlling for income, the negative correlation was no longer significant. This result may reflect differences in lifestyle orientations, for instance among people who are more work-oriented and those who devote more time to leisure activities (e.g., Ohnmacht et al., 2009). A slightly different interpretation may be drawn from an analysis of the differences between clusters. People with home-centered active-travel oriented ASs reported markedly higher satisfaction with their own health and quality of the environment. Compared to others, these people participated more in leisure, social, and cultural activities and less in work- and childcare-related activities. They more often live in walkable and densely built environments that support social interaction outside the home. One may speculate that it is the characteristic of the environment that supports such positive effects on this aspect of wellbeing. Conversely, people with polycentric car-oriented ASs scored highest on achievement satisfaction. These people reportedly focus more on work- and family-related activities than on leisure, spend more time working, earn more, are generally older, and more often have children and long-term relationships. All these factors may contribute to satisfaction with occupation and the things people achieve in their life. It should be noted that the differences between clusters may be also be attributed to differences in the life-cycle stage as well as lifestyle preferences (i.e., attitudes and orientations) (van Acker et al., 2010).

Interestingly, lifestyle orientation towards work and/or family, as well as satisfaction with these domains, correlated with a high level of car use. Similar differences in mobility patterns of the "workoriented" and "urbanist" groups have been previously described in several transportation studies (Krizek \& Waddell, 2002; Lu \& Pas, 1999). The lifestyle orientations and attitudes may also be the reason why people with Public transportation-oriented ASs scored lowest on most wellbeing measures. The low wellbeing measures in this cluster are in line with previous research finding a negative effect of public transportation use on different domains of life satisfaction (Friman, Gärling, Ettema, \& Olsson, 2017). This finding may also be attributed to the higher elongation of ASs as well as the relatively lower income of people in this group, both previously found to be associated with lower subjective wellbeing (Buliung \& Kanaroglou, 2006; Ludwig et al., 2012). However, for more conclusive interpretations further studies are needed. Future studies should also take into account differences in lifestyle orientations and attitudes.

The interpretability of the empirical results, together with their congruence with well-established findings from previous studies, provide support for the validity of the methodological framework proposed in this study. The significant contribution of measurements to the identification of AS dimensions, and in turn, the capability of dimensions to reveal relationships between AS and other data, add to the validity of this study's primary assumption that ASs are multidimensional and can best be studied via a multidimensional approach. Each dimension may shed light on a certain aspect of AS, and its exclusion may hinder a comprehensive understanding of the study subject.

Despite the empirical and methodological contribution of the study, it is not free from limitations. The online mapping survey used in the study may have resulted in some measurement biases. However, PPGIS surveys have been implemented in numerous studies and evidences show that their spatial accuracy is generally acceptable (Brown, 2012). Moreover, some of the measures we employed rely on the number of locations marked on a map. These measures may be confounded by the level of the respondents' engagement with mapping activities and the level of their mapping skills (Brown, 2016).

Another potential limitation of this study is that seasonality is not accounted for when measuring mobility. It was left to the participants to identify and report their average mobility, and this can cause biases since such behaviors can change seasonally. However, the errors pertain to individual participants, and there is no known reasons for the errors being systematically related to the variables of interest in the study. Therefore, we can safely assume that individual errors do not introduce strong bias to the aggre- 
gate analysis presented in the article. In this regard, it will be interesting to see future research focusing on tackling these limitations. This can, for instance, be done by improving data quality through combining other datasets, such as GPS tracking or mobile phone data. Furthermore, the biases introduced by the survey can be potentially ameliorated through improved designs and a more comprehensive measurement of wellbeing factors.

\section{Conclusion}

In summary, this paper demonstrated the pertinence of using a holistic approach to relate characteristics of activity space (AS), urban form, and wellbeing in a multidimensional way. As the first step in this article, we created a model of individual ASs followed by measurement and identification of their seven descriptive dimensions. Next, we identified a typology of ASs, including three types of mobility behavior based on different dimensions of ASs and use of travel modes.

The typology of ASs, incorporating both geometrical and travel-related dimensions of ASs is a promising step toward a more holistic analysis of individual ASs. Despite the statistically significant contribution of most AS dimensions to the identification of this typology, the results indicate that the use of travel modes can significantly contribute to our understanding of ASs. Additionally, the three identified AS types, show significant differences in terms of socio-demographic characteristics of their members. Particularly, factors such as age, gender, employment, household characteristics, and residential neighborhood appear to considerably vary between these groups.

Furthermore, an investigation of different AS characteristics in relation to the perceived wellbeing factors indicate considerable associations. In addition to socio-demographic variables, especially income which is positively associated with most wellbeing measures, some AS dimensions show strong associations with some of the wellbeing aspects. Particularly, exteriority of AS appears as a negative correlate of most wellbeing measures, whereas intensity shows positive correlations. Additionally, the comparison of wellbeing measures between the three AS types shows significant differences on most measures. This provides us with new insights to the relationships between wellbeing and AS type. In essence, satisfaction with certain domains of wellbeing seems to be associated with mobility styles. For example, people with better job and study satisfaction appear to have more polycentric and car-oriented ASs, whereas, better satisfaction with health, safety, and leisure time appears to be associated with more active and concentrated mobility style.

Overall, the results demonstrate the relevance of using more holistic and multidimensional approaches as different measures and measuring approaches shed light on different aspects of the relationships. The results also point to the relevance of using a clustered approach to identify different AS classes based on the mobility behavior of individuals. A multidimensional measurement of ASs, together with a clustered approach, can provide an effective means by which to properly assess the potential impacts of mobility, urban form, and transportation interventions. In a policy context, the segmentation of ASs may be used to guide social marketing campaigns aimed at changing mobility patterns and to improve understanding of people's behavior.

However, there is still need for further research and improvement of the presented methods. One approach that can potentially improve the analytical accuracy of the study framework is to investigate other novel AS measures. This can result in the identification of additional dimensions of mobility behavior and positively contribute to the quality of the clustering approach. Future research can benefit from the use of better-designed surveys aiming to ameliorate the biases and limitations present in this study. It would also be interesting to see future research investigating and comparing the existence of a similar typology of ASs in other geographical areas. However, it should be noted that the measurements presented in this study are context-sensitive and any interpretation of the results should be evaluated based on the context and the theme of the study. 


\section{Acknowledgements}

This research is primarily funded by the Academy of Finland as part of PLANhealth project (13297753). The funding for this research is also partially provided by University of Iceland Research Fund. 


\section{References}

Axhausen, K. W. (2003). Social networks and travel: Some hypotheses. Transport and Society, 197, 90108. doi.org/10.3929/ethz-a-004663201

Banister, D. (2008). The sustainable mobility paradigm. Transport Policy, 15(2), 73-80. doi. org/10.1016/j.tranpol.2007.10.005

Bertram, C., \& Rehdanz, K. (2015). The role of urban green space for human well-being. Ecological Economics, 120, 139-152. doi.org/10.1016/j.ecolecon.2015.10.013

Brown, G. (2012). An empirical evaluation of the spatial accuracy of public participation GIS (PPGIS) data. Applied Geography, 34, 289-294. doi.org/10.1016/J.APGEOG.2011.12.004

Brown, G. (2016). A review of sampling effects and response bias in internet participatory mapping (PPGIS/PGIS/VGI). Transactions in GIS. doi.org/10.1111/tgis.12207

Brown, G., \& Kyttä, M. (2014). Key issues and research priorities for public participation GIS (PPGIS): A synthesis based on empirical research. Applied Geography, 46, 126-136. doi.org/10.1016/j. apgeog.2013.11.004

Buliung, R. N., \& Kanaroglou, P. S. (2006). Urban form and household activity-travel behavior. Growth and Change, 37(2), 172-199. doi.org/10.1111/j.1468-2257.2006.00314.x

Buliung, R. N., Roorda, M. J., \& Remmel, T. K. (2008). Exploring spatial variety in patterns of activitytravel behavior: Initial results from the Toronto Travel-Activity Panel Survey (TTAPS). Transportation, 35(6), 697-722. doi.org/10.1007/s11116-008-9178-4

Burnett, P., \& Hanson, S. (1982). The analysis of travel as an example of complex human behavior in spatially-constrained situations: Definition and measurement issues. Transportation Research Part A: General, 16(2), 87-102. doi.org/10.1016/0191-2607(82)90001-2

Creatore, M. I., Glazier, R. H., Moineddin, R., Fazli, G. S., Johns, A., Gozdyra, P.,...Booth, G. L. (2016). Association of neighborhood walkability with change in overweight, obesity, and diabetes. Journal of the American Medical Association, 315(20), 2211-2220. doi.org/10.1001/jama.2016.5898

Czepkiewicz, M., Jankowski, P., \& Młodkowski, M. (2016). Geo-questionnaires in urban planning: Recruitment methods, participant engagement, and data quality. Cartography and Geographic Information Science, 44(6), 551-567. doi.org/10.1080/15230406.2016.1230520

de Hartog, J. J., Boogaard, H., Nijland, H., \& Hoek, G. (2010). Do the health benefits of cycling outweigh the risks? Environmental Health Perspectives. doi.org/10.1289/ehp.0901747

Dijst, M. (1999). Two-earner families and their action spaces: A case study of two Dutch communities. GeoJournal, 48(3), 195-206. doi.org/10.1023/A:1007031809319

Dodge, R., Daly, A., Huyton, J., \& Sanders, L. (2012). The challenge of defining wellbeing. International Journal of Wellbeing, 2(3), 222-235. doi.org/10.5502/ijw.v2i3.4

Ewing, R., \& Cervero, R. (2010). Travel and the built environment. Journal of the American Planning Association, 76(3), 265-294. doi.org/10.1080/01944361003766766

Fan, Y., \& Khattak, A. (2008). Urban form, individual spatial footprints, and travel: Examination of space-use behavior. Transportation Research Record: Journal of the Transportation Research Board, 2082, 98-106.

Farber, S., \& Páez, A. (2009). My car, my friends, and me: A preliminary analysis of automobility and social activity participation. Journal of Transport Geography, 17(3), 216-225. doi.org/10.1016/j. jtrangeo.2008.07.008

Flamm, M. F., \& Kaufmann, V. (2006). The concept of personal network of usual places as a tool for analyzing human activity spaces: A quantitative exploration. Conference Paper STRC 2006. doi. org/10.1108/02580540410567256

Friman, M., Gärling, T., Ettema, D., \& Olsson, L. E. (2017). How does travel affect emotional well- 
being and life satisfaction? Transportation Research Part A: Policy and Practice, 106, 170-180. doi. org/10.1016/J.TRA.2017.09.024

Frumkin, H. (2002). Urban sprawl and public health. Public Health Reports. doi.org/10.1016/S00333549(04)50155-3

Gatersleben, B., \& Uzzell, D. (2007). Affective appraisals of the daily commute: Comparing perceptions of drivers, cyclists, walkers, and users of public transport. Environment and Behavior, 39(3), 416-431. doi.org/10.1177/0013916506294032

Glazier, R. H., Creatore, M. I., Weyman, J. T., Fazli, G., Matheson, F. I., Gozdyra, P., ... Booth, G. L. (2014). Density, destinations or both? A comparison of measures of walkability in relation to transportation behaviors, obesity and diabetes in Toronto, Canada. PLoS ONE, 9(1). doi.org/10.1371/ journal.pone.0085295

Hägerstraand, T. (1970). What about people in regional science? Papers in Regional Science, 24(1), 7-24.

Handy, S. L., Boarnet, M. G., Ewing, R., \& Killingsworth, R. E. (2002). How the built environment affects physical activity. American Journal of Preventive Medicine, 23(2), 64-73. doi.org/10.1016/ S0749-3797(02)00475-0

Hanson, S., \& Hanson, P. (1981). The travel-activity patterns of urban residents: Dimensions and relationships to sociodemographic characteristics. Economic Geography, 57(4), 332-347. doi. org/10.2307/144213

Harding, C., Patterson, Z., Miranda-Moreno, L., \& Zahabi, S. (2012). Modeling the effect of land use on activity spaces. Transportation Research Record: Journal of the Transportation Research Board, 2323, 67-74. doi.org/10.3141/2323-08

Hasanzadeh, K. (2018). IASM: Individualized activity space modeler. SoftwareX, 7, 138-142. Retrieved from https://www.sciencedirect.com/science/article/pii/S2352711018300542

Hasanzadeh, K. (2019). Exploring centricity of activity spaces: From measurement to the identification of personal and environmental factors. Travel Behavior and Society, 14, 57-65. doi.org/10.1016/J. TBS.2018.10.001

Hasanzadeh, K., Broberg, A., \& Kyttä, M. (2017). Where is my neighborhood? A dynamic individual-based definition of home zones. Applied Geography, 84(C), 1-10. doi.org/10.1016/j.apgeog.2017.04.006

Hasanzadeh, K., Laatikainen, T., \& Kyttä, M. (2018). A place-based model of local activity spaces: Individual place exposure and characteristics. Journal of Geographical Systems, 20(3), 227. doi. org/10.1007/s10109-017-0264-z

Haustein, S., \& Hunecke, M. (2013). Identifying target groups for environmentally sustainable transport: Assessment of different segmentation approaches. Current Opinion in Environmental Sustainability. doi.org/10.1016/j.cosust.2013.04.009

Haybatollahi, M., Czepkiewicz, M., Laatikainen, T., \& Kyttä, M. (2015). Neighborhood preferences, active travel behavior, and built environment: An exploratory study. Transportation Research Part F: Traffic Psychology and Behavior, 29, 57-69. doi.org/10.1016/j.trf.2015.01.001

Hoehner, C. M., Handy, S. L., Yan, Y., Blair, S. N., \& Berrigan, D. (2011). Association between neighborhood walkability, cardiorespiratory fitness and body-mass index. Social Science and Medicine, 73(12), 1707-1716. doi.org/10.1016/j.socscimed.2011.09.032

Horton, F. E. H., \& Reynolds, D. R. (1971). Effects of urban spatial structure on individual behavior. Economic Geography, 47(1), 36-48. doi.org/10.1126/science.11.277.620

Hwang, H., Montréal, H., Dillon, W. R., \& Takane, Y. (2006). An extension of multiple correspondence analysis for identifying heterogeneous subgroups of respondents. Psychometrika, 71(1), 161171. doi.org/10.1007/s11336-004-1173-x

International Wellbeing Group (2013). Personal wellbeing index: 5th Edition. Melbourne: Australian 
Centre on Quality of Life, Deakin University. Retrieved from http://www.deakin.edu.au/research/ acqol/instruments/wellbeing-index/index.php

Jarv, O., Muurisepp, K., Ahas, R., Derudder, B., \& Witlox, F. (2015). Ethnic differences in activity spaces as a characteristic of segregation: A study based on mobile phone usage in Tallinn, Estonia. Urban Studies, 52(14), 2680-2698. doi.org/10.1177/0042098014550459

Kahila, M., \& Kyttä, M. (2009). SoftGIS as a bridge-builder in collaborative urban planning. In Geojournal Library, Vol 95 (pp. 389-411). Basingstoke, UK: Springer Nature. doi.org/10.1007/978-14020-8952-7_19

Kahneman, D., Krueger, A. B., Schkade, D. A., Schwarz, N., \& Stone, A. A. (2004). A survey method for characterizing daily life experience: The day reconstruction method. Science, 306(5702), 17761780. doi.org/10.1126/science. 1103572

Kamruzzaman, M., \& Hine, J. (2012). Analysis of rural activity spaces and transport disadvantage using a multi-method approach. Transport Policy, 19(1), 105-120. doi.org/10.1016/J.TRANPOL.2011.09.007

Kenyon, S., Lyons, G., \& Rafferty, J. (2002). Transport and social exclusion: Investigating the possibility of promoting inclusion through virtual mobility. Journal of Transport Geography, 10(3), 207-219.

Krizek, K., \& Waddell, P. (2002). Analysis of lifestyle choices: Neighborhood type, travel patterns, and activity participation. Transportation Research Record: Journal of the Transportation Research Board, 1807, 119-128. doi.org/10.3141/1807-15

Kwan, M.-P. (2012a). Geographies of health. Annals of the Association of American Geographers, 102(5), 891-892. doi.org/10.1080/00045608.2012.687348

Kwan, M.-P. (2012b). The uncertain geographic context problem. Annals of the Association of American Geographers, 102, 958-968. doi.org/10.1080/00045608.2012.687349

Kwan, M.-P., \& Schwanen, T. (2016). Geographies of mobility. Annals of the American Association of Geographers, 106(2), 243-256. doi.org/10.1080/24694452.2015.1123067

Laatikainen, T. E., Hasanzadeh, K., \& Kyttä, M. (2018). Capturing exposure in environmental health research: Challenges and opportunities of different activity space models. International Journal of Health Geographics, 17(1), 29.

Lebart, L., Morineau, A., \& Piron, M. (2000). Statistique exploratoire multidimensionnelle. Paris: Dunod. Retrieved from https://books.google.fr/books/about/Statistique_exploratoire_multidimensionn. html?hl=fr\&id=CS5KHQAACAAJ

Lee, N. C., Voss, C., Frazer, A. D., Hirsch, J. A., McKay, H. A., Winters, M., ... Winters, M. (2015). Does activity space size influence physical activity levels of adolescents? A GPS study of an urban environment. Preventive Medicine Reports, 3, 75-78. doi.org/10.1016/j.pmedr.2015.12.002

Lord, S., Joerin, F., \& Thériault, M. (2009). La mobilité quotidienne de banlieusards vieillissants et âgés: Déplacements, aspirations et significations de la mobilité. Le Géographe Canadien, 53(3), 357-375. doi.org/10.1111/j.1541-0064.2009.00269.x

Lu, X., \& Pas, E. I. (1999). Socio-demographics, activity participation and travel behavior. Transportation Research Part A: Policy and Practice, 33(1), 1-18. doi.org/10.1016/S0965-8564(98)00020-2

Ludwig, J., Duncan, G. J., Gennetian, L. A., Katz, L. F., Kessler, R. C., Kling, J. R., \& Sanbonmatsu, L. (2012). Neighborhood effects on the long-term well-being of low-income adults. Science, 337(6101), 1505-1510. doi.org/10.1126/science. 1224648

Manaugh, K., \& El-Geneidy, A. (2012). What makes travel "local": Defining and understanding local travel behavior. Journal of Transport and Land Use, 5(3), 15-27. doi.org/10.5198/jtlu.v5i3.300

Meng, X. U. (2014). The impact of labor migration on regional disparities in economic growth. Journal of Zhanjiang Normal University, 3, 29.

Millard-Ball, A., \& Schipper, L. (2011). Are we reaching peak travel? Trends in passenger transport in eight industrialized countries. Transport Reviews, 31(3), 357-378. doi.org/10.1080/01441647.201 
0.518291

Miranda-Moreno, L. F., Eluru, N., Lee-Gosselin, M., \& Kreider, T. (2012). Impact of ICT access on personal activity space and greenhouse gas production: Evidence from Quebec City, Canada. Transportation, 39(5), 895-918. doi.org/10.1007/s11116-012-9428-3

Morris, E. A., \& Guerra, E. (2014). Mood and mode: Does how we travel affect how we feel? Transportation, 42(1), 25-43. doi.org/10.1007/s11116-014-9521-x

Naess, P. (2012). Urban form and travel behavior: Experience from a Nordic context. Journal of Transport and Land Use, 5, 21-45. doi.org/10.5198/jtlu.v5i2.314

Næss, P. (2013). Residential location, transport rationales and daily-life travel behavior: The case of Hangzhou metropolitan area, China. Progress in Planning, 79(1), 1-50. doi.org/10.1016/j.progress.2012.05.001

Newman, P., Kosonen, L., \& Kenworthy, J. (2016). Theory of urban fabrics: Planning the walking, transit/public transport and automobile/motor car cities for reduced car dependency. Town Planning Review, 87(4), 429-458. doi.org/10.3828/tpr.2016.28

Newsome, T. H., Walcott, W. A., \& Smith, P. D. (1998). Urban activity spaces: Illustrations and application of a conceptual model for integrating the time and space dimensions. Transportation, 25(4), 357-377. doi.org/10.1023/A:1005082827030

Northridge, M. E., \& Freeman, L. (2011). Urban planning and health equity. Journal of Urban Health, 88(3), 582-597. doi.org/10.1007/s11524-011-9558-5

OECD. (2013). OECD guidelines on measuring subjective well-being. Paris: OECD. Retrieved from http://dx.doi.org/10.1787/9789264191655-en

Ohnmacht, T., Götz, K., \& Schad, H. (2009). Leisure mobility styles in Swiss conurbations: Construction and empirical analysis. Transportation, 36(2), 243-265. doi.org/10.1007/s11116-009-9198-8

Patterson, Z., \& Farber, S. (2015). Potential path areas and activity spaces in application: A review. Transport Reviews, 35(6), 679-700. doi.org/10.1080/01441647.2015.1042944

Perchoux, C., Chaix, B., Cummins, S., \& Kestens, Y. (2013). Conceptualization and measurement of environmental exposure in epidemiology: Accounting for activity space related to daily mobility. Health \& Place, 21, 86-93. doi.org/10.1016/j.healthplace.2013.01.005

Perchoux, C., Kestens, Y., Thomas, F., van Hulst, A., Thierry, B., \& Chaix, B. (2014). Assessing patterns of spatial behavior in health studies: Their socio-demographic determinants and associations with transportation modes (the RECORD Cohort Study). Social Science and Medicine, 119, 64-73. doi. org/10.1016/j.socscimed.2014.07.026

Perez, L. G., Conway, T. L., Bauman, A., Kerr, J., Elder, J. P., Arredondo, E. M., \& Sallis, J. F. (2018). Sociodemographic moderators of environment-physical activity associations: Results from the international prevalence study. Journal of Physical Activity and Health, 15(1), 22-29. doi.org/10.1123/ jpah.2017-0163

Prillwitz, J., \& Barr, S. (2011). Moving towards sustainability? Mobility styles, attitudes and individual travel behavior. Journal of Transport Geography, 19(6), 1590-1600. doi.org/10.1016/j.jtrangeo.2011.06.011

Pucher, J., Buehler, R., Bassett, D. R., \& Dannenberg, A. L. (2010). Walking and cycling to health: A comparative analysis of city, state, and international data. American Journal of Public Health, 100(10), 1986-1992. doi.org/10.2105/AJPH.2009.189324

Putnam, R. D. (2000). Bowling alone: The collapse and revival of American community. New York: Simon and Schuster.

Rai, P., \& Daumé III, H. (n.d.). The Infinite hierarchical factor regression model. Retrieved from http:// people.ee.duke.edu/_lcarin/FA_BuffetProcess_NIPS08.pdf 
Rai, R., Balmer, M., Rieser, M., Vaze, V., Schönfelder, S., \& Axhausen, K. (2007). Capturing human activity spaces: New geometries. Transportation Research Record: Journal of the Transportation Research Board, 2021, 70-80. doi.org/10.3141/2021-09

Rainham, D., McDowell, I., Krewski, D., \& Sawada, M. (2010). Conceptualizing the healthscape: Contributions of time geography, location technologies and spatial ecology to place and health research. Social Science and Medicine, 70(5), 668-676. doi.org/10.1016/j.socscimed.2009.10.035

Richardson, E. A., Pearce, J., Mitchell, R., \& Kingham, S. (2013). Role of physical activity in the relationship between urban green space and health. Public Health, 127(4), 318-324. doi.org/10.1016/j. puhe.2013.01.004

Salonen, M., Broberg, A., Kyttä, M., \& Toivonen, T. (2014). Do suburban residents prefer the fastest or low-carbon travel modes? Combining public participation GIS and multimodal travel time analysis for daily mobility research. Applied Geography, 53, 438-448. doi.org/10.1016/j.apgeog.2014.06.028

Sarjala, S.-M., Broberg, A., \& Hynynen, A. (2015). Children and youth transport in different urban morphological types. Journal of Transport and Land Use, 9(2), 87-103. doi.org/10.5198/ jtlu.2015.803

Schönfelder, S., \& Axhausen, K. (2004). Structure and innovation of human activity spaces. Arbeitsberichte Verkehrs-Und Raumplanung, 258(October), 1-40.

Schönfelder, S., \& Axhausen, K. W. (2002a). Measuring the size and structure of human activity spaces. Transportation Research, (February), 49. doi.org/10.3929/ethz-a-004444846

Schönfelder, S., \& Axhausen, K. W. (2002b). On the variability of human activity spaces. Arbeitsbericht Verkehrs-Und Raumplanung, 149, 237-262.

Schönfelder, S., \& Axhausen, K. W. (2003). Activity spaces: Measures of social exclusion? Transport Policy, 10(4), 273-286. doi.org/10.1016/j.tranpol.2003.07.002

Shephard, R. J. (2008). Is active commuting the answer to population health? Sports Medicine, 38(9), 751-758. doi.org/10.2165/00007256-200838090-00004

Sherman, J. E., Spencer, J., Preisser, J. S., Gesler, W. M., \& Arcury, T. A. (2005). A suite of methods for representing activity space in a healthcare accessibility study. International Journal of Health Geographics, 4(1), 24. doi.org/10.1186/1476-072X-4-24

Shin, D. C., \& Johnson, D. M. (1978). Avowed happiness as an overall assessment of the quality of life. Social Indicators Research, 5(1-4), 475-492. doi.org/10.1007/BF00352944

Söderström, P., Schulman, H., \& Ristimäki, M. (2015). Urban form in the Helsinki and Stockholm city regions-Development of pedestrian, public transport and car zones. Report of the Finnish Environment Institute No. 16/2015. Retrieved from https://helda.helsinki.fi/handle/10138/155224

Stutzer, A., \& Frey, B. S. (2008). Stress that doesn't pay: The commuting paradox. Scandinavian Journal of Economics, 110(2), 33 9-366. doi.org/10.1111/j.1467-9442.2008.00542.x

Tana, Kwan, M.-P., Chai, Y. (2016). Urban form, car ownership and activity space in inner suburbs: A comparison between Beijing (China) and Chicago (United States). Urban Studies, 53(9), 1784 1802.

Vallée, J., Cadot, E., Roustit, C., Parizot, I., \& Chauvin, P. (2011). The role of daily mobility in mental health inequalities: The interactive influence of activity space and neighborhood of residence on depression. Social Science \& Medicine, 73(8), 1133-1144. doi.org/10.1016/j.socscimed.2011.08.009

van Acker, V., van Wee, B., \& Witlox, F. (2010). When transport geography meets social psychology: Toward a conceptual model of travel behavior. Transport Reviews, 30(2), 219-240. doi. org/10.1080/01441640902943453

WHOQOL. (1993). Study protocol for the World Health Organization project to develop a quality of life assessment instrument (WHOQOL). Quality of Life Research, 2(2), 153-159. doi.org/ 


$$
\text { doi:10.1007/bf00435734 }
$$

Xu, Y., Shaw, S.-L., Zhao, Z., Yin, L., Lu, F., Chen, J., ... Li, Q. (2016). Another tale of two cities: Understanding human activity space using actively tracked cellphone location data. Annals of the American Association of Geographers, 106(2), 489-502. doi.org/10.1080/00045608.2015.1120147

\section{Appendices}

Appendices 1, 2, and 3 are available in a supplemental file at: www.jtlu.org/index.php/jtlu/rt/suppFiles/1148/0. 